\title{
PERANAN PENAGIHAN TUNGGAKAN PAJAK TERHADAP PERTUMBUHAN TUNGGAKAN PAJAK
}

\author{
Ovilya Rambu Ana Awa ${ }^{1}$ dan Norman Duma Sitinjak ${ }^{2}$ \\ ${ }^{1}$ Fakultas Ekonomi dan Bisnis Universitas Merdeka Malang \\ ovilyarambu@gmail.com \\ ${ }^{2}$ Universitas Merdeka Malang \\ norman1274@yahoo.com
}

\begin{abstract}
This study aimed to analyze the effectiveness of the collection of tax arrears on STO Stone and to analyze the contribution of delinquent tax collection to the final balance of tax arrears on STO Stone. Taxes become the backbone of cash income for the country, therefore the government ensures that the tax revenue to meet the target. But it does not always go smoothly. Arrears can occur either because of a lack of awareness of taxpayers and the inability of taxpayer funds to pay their tax debts. To handle this, the government, or in this case the Tax Office Primary spearhead that tax arrears may be getting smaller over time. Target's disbursement of tax arrears that have been determined by the Regional Office with a wide range of considerations. The effectiveness of tax arrears collection that demonstrates the ability of the collection of tax arrears based on the amount of tax revenue over the billing section targeted. The biggest tax arrears from 2012 to 2013, due to the balance of the year 2012 plus a legal product which was published in 2013 reduced payments or reductions in 2013.
\end{abstract}

Keywords: effectiveness and tax arrears

\section{PENDAHULUAN}

Setelah masa Orde Baru (Orba), pajak menjadi sumber penerimaan negara yang terbesar. Kecenderungannya semakin meningkat dari tahun ke tahun. Untuk lebih memaksimalkan peneriman pajak, pemerintah telah mengambil langkahlangkah kebijakan agar dapat meningkatkan kesadaran Wajib Pajak (WP).

Kendala dalam penerimaan pajak selalu ada, diantaranya adalah WP yang terlambat atau tidak membayar pajak terutangnya. Untuk mengatasi itu salah satu upaya yang dilakukan pemerintah adalah dengan tindakan penagihan tunggakan pajak.

Penagihan tunggakan pajak merupakan wujud upaya untuk sarana pencairan tunggakan pajak, meliputi pemberitahuan Surat Teguran, pemberitahuan Surat Paksa, melaksanakan penyitaan, melaksanakan penyanderaan, dan/atau menjual barang yang telah disita berdasarkan ketentuan yang diatur dalam Undang-Undang
Nomor 19 Tahun 1997 tentang Penagihan Pajak dengan Surat Paksa sebagaimana telah diubah dengan Undang-Undang Nomor 19 Tahun 2000. Diupayakan agar setiap WP mendapatkan giliran untuk diperiksa dalam rangka menguji pemenuhan kewajiban perpajakannya. Jika WP setelah ditagih pun belum memenuhi penagihan pajak, maka Kantor Pelayanan Pajak (KPP) berhak menagih dengan Surat Paksa sesuai dengan hukum perpajakan. Dengan efektifnya penagihan pajak akan dapat meningkatkan penerimaan pajak yang diharapkan dapat memberikan kontribusi terhadap pembangunan nasional.

\section{Rumusan Masalah}

Berdasarkan beberapa hal yang diuraikan dalam alasan pemilihan judul, maka rumusan permasalahannya sebagai berikut :

1. Bagaimana efektivitas penagihan tunggakan pajak? 
2. Bagaimana dampak kontribusi tunggakan pajak terhadap saldo akhir tunggakan pajak?

\section{Tujuan Penelitian}

1. Untuk menganalisis efektivitas penagihan tunggakan pajak pada KPP Pratama Batu.

2. Untuk menganalisis kontribusi penagihan pajak tunggakan terhadap saldo akhir tunggakan pajak pada KPP Pratama Batu.

\section{LANDASAN TEORI}

\section{Pengertian pajak}

Menurut Waluyo (2009:2) Pajak merupakan iuran dari rakyat kepada negara yang diatur Undang-Undang untuk membiayai kegiatan negara dan pembayar pajak tidak dapat imbalan secara langsung. Karena berdasarkan Undang-Undang maka pemungutannya dapat dipaksakan. Jika tidak mentaati akan mendapat sanksi tidak mendapat imbalan langsung karena ditujukan untuk pendanaan negara dalam melayani masyarakat.

\section{Fungsi pajak}

Secara garis besar pajak memiliki dua fungs, yaitu (Mardiasmo, 2011:1):
a. Fungsi Penerimaan (Budgetary)
Pajak berfungsi sebagai sumber keuangan bagi negara.
b. Fungsi Mengatur (Regulatory)
Pajak juga berfungsi sebagai alat untuk mendukung kebijakan pemerintah.

\section{Jenis-Jenis Pajak}

Resmi (2014:7) mengelompokkan jenis-jenis pajak sebagai berikut :

Pajak dikelompokkan menjadi dua, yaitu :

1) Pajak Langsung
Pajak yang terutang harus dipikul atau ditanggung sendiri oleh WP dan tidak dapat dilimpahkan atau dibebankan kepada orang lain atau pihak lain. Contohnya yaitu Pajak Penghasilan (PPh).

2) Pajak Tidak Langsung

Pajak yang terutang dapat dilimpahkan kepada pihak lain. Contohnya yaitu Pajak Pertambahan Nilai (PPN)

\section{Sistem Pemungutan Pajak}

Sistem pemungutan terdiri dari

1) Official Assessment System. Sistem pemungutan yang memberi wewenang kepada pemerintah (fiskus) untuk menentukan besarnya pajak yang terutang oleh WP.

2) Self Assessment System. Sistem pemungutan pajak yang memberi wewenang kepada WP untuk menentukan besarnya pajak yang terutang.

3) With Holding System. Sistem pemungutan pajak yang memberi wewenang kepada pihak ketiga (bukan fiskus dan bukan WP yang bersangkutan) untuk menentukan besarnya pajak yang terutang oleh WP.

\section{Surat Ketetapan Pajak (SKP)}

SKP terbatas hanya kepada WP tertentu yang disebabkan oleh ketidakbenaran dalam pengisian Surat Pemberitahuan (SPT) atau karena ditemukannya data fisik yang tidak dilaporkan oleh WP. Surat ini diterbitkan setelah proses pemeriksaan selesai dilakukan dan belum dilakukan penyidikan.

Surat Ketetapan Pajak terdiri atas enam macam, yaitu Surat Tagihan Pajak (STP), surat keterangan berupa Surat Ketetapan Pajak Kurang Bayar (SKPKB), Surat Ketetapan Pajak Kurang Bayar Tambahan (SKPKBT), Surat Ketetapan Pajak 
Lebih Bayar (SKPLB), Surat Ketetapan Pajak Nihil (SKPN), dan Surat Pemberitahuan Pajak Terutang (SPPT).

\section{Surat Tagihan Pajak (STP)}

Surat yang untuk melakukan tagihan pajak dan/atau sanksi administrasi berupa bunga dan/atau denda. Surat Tagihan Pajak diatur dalam Pasal 14 UU No.6 Tahun 1983 tentang Ketentuan Umum dan Tata Cara Perpajakan sebagaimana telah diubah dengan UU No.6 Tahun 2000. Surat Tagihan Pajak dapat diterbitkan dalam hal-hal sebagai berikut:

2. Surat Ketetapan Pajak Kurang Bayar (SKPKB)

Surat yang menentukan besarnya jumlah pokok pajak, jumlah kredit pajak, jumlah kekurangan pembayaran pokok pajak, besarnya sanksi administrasi, dan jumlah yang masih harus dibayar.

\section{Surat Ketetapan Pajak Kurang Bayar} Tambahan (SKPKBT)

Surat yang diterbitkan untuk menentukan tambahan atas jumlah pajak yang telah ditetapkan dalam SKPKBT. Penerbitan SKPKBT dilakukan apabila ditemukan data baru dan/atau data yang semula belum terungkap yang dapat menyebabkan penambahan pajak yang terutang.

\section{Surat Ketetapan Pajak Lebih Bayar (SKPLB)}

Surat yang diterbitkan untuk menentukan jumlah kelebihan pembayaran pajak karena jumlah kredit pajak lebih besar daripada pajak yang terutang atau tidak seharusnya terutang. SKPLB diterbitkan jika ada permohonan tertulis dari WP.

\section{Surat Ketetapan Pajak Nihil (SKPN)}

Surat yang diterbitkan untuk menentukan jumlah pokok pajak sama besarnya dengan jumlah kredit pajak atau pajak tidak terutang dan tidak ada kredit pajak.

\section{Surat Pemberitahuan Pajak Terutang (SPPT)}

Surat yang diterbitkan oleh Direktorat Jenderal Pajak untuk memberitahukan besarnya pajak yang terutang kepada WP.

\section{Penagihan Pajak}

Pengertian dalam pasal 1 butir 9 Undangundang No. 19 Tahun 2000 penagihan pajak adalah serangkaian tindakan agar penanggung pajak melunasi utang pajak dan biaya penagihan pajak dengan menegur atau memperingatkan, melaksanakan penagihan seketika dan sekaligus memberitahukan surat paksa, mengusulkan pencegahan, melaksanakan penyitaan, melaksanakan penyanderaan, menjual barang yang telah disita (Rahayu, 2010:197), dibagi menjadi tiga:

1. Penagihan Pajak Pasif

Dilakukan dengan menggunakan Surat Tagihan Pajak (STP), Surat Ketetapan Pajak Kurang Bayar (SKPKB), Surat Ketetapan Pajak Kurang Bayar Tambahan (SKPKBT), surat keputusan pembetulan yang menyebabkan pajak terutang menjadi lebih besar, surat keputusan keberatan yang menyebabkan pajak terutang menjadi lebih besar. Jika dalam jangka waktu 30 (tiga puluh) hari belum dilunasi, maka tujuh hari setelah jatuh tempo akan diikuti dengan penagihan pajak secara aktif yang dimulai dengan menerbitkan surat teguran.

2. Penagihan Pajak Aktif

Penagihan pajak aktif merupakan kelanjutan dari penagihan pajak pasif, dimana dalam upaya penagihan ini fiskus berperan aktif dalam arti 
tidak hanya mengirim surat tagihan atau surat ketetapan pajak tetap, akan diikuti denan tindakan sita, dan dilanjutkan dengan pelaksanaan lelang.

\section{Tunggakan Pajak}

Tunggakan pajak adalah besarnya pajak terutang yang belum dibayarkan

1. Oleh WP. Tunggakan pajak ini disebabkan oleh 2 (dua) hal, yaitu:

a. Karena pemeriksaan, yang meliputi:

1) Surat Ketetapan Pajak (SKP). Surat Ketetapan Pajak (SKP) ini diterbitkan terbatas pada Wajib Pajak tertentu yang disebabkan oleh ketidakbenaran dalam pengisian Surat Pemberitahuan (SPT) atau karena ditemukannya data fisik yang tidak dilaporkan oleh WP.

2) Surat Tagihan Pajak (SPT) adalah surat untuk melakukan penagihan pajak dan atau sanksi administrasi berupa bunga dan atau denda bagi WP.

b. Karena WP tidak mampu membayar kewajiban Dalam hal ini tuggakan timbul karena murni yang bersangkutan atau Wajib Pajak tidak dapat memenuhi kewajiban perpajakannya. Apabila bidang penagihan mendapati adanya tunggakan yang disebabkan seperti diatas, maka akan dilakukan tindakan penagihan aktif sebagai sarana untuk menagih pajak kepada WP.

2. Tindakan Penagihan Pajak

a. Pengertian Penagihan Pajak Menurut Undang-undang Nomor 19 Tahun 2000 penagihan pajak adalah serangkaian tindakan agar Penanggung Pajak melunasi utang pajak dan biaya penagihan pajak dengan menegur atau memperingatkan, melaksanakan penagihan seketika dan sekaligus, memberitahukan surat paksa, mengusulkan pencegahan, melaksanakan penyitaan, melaksanakan penyanderaan, menjual barang yang telah disita.

b. Tindakan Penagihan Pajak Pasif

Penagihan pajak pasif dilakukan dengan menggunakan Surat Tagihan Pajak (STP), Surat Ketetapan Pajak Kurang Bayar (SKPKB), Surat Ketetapan Pajak Kurang Bayar Tambahan (SKPKBT), surat keputusan pembetulan yang menyebabkan pajak terutang menjadi lebih besar, surat keputusan keberatan yang menyebabkan pajak terutang menjadi lebih besar, surat keputusan banding yang menyebabkan pajak terutang menjadi lebih besar. Jika dalam jangka waktu 30 hari belum dilunasi, maka 7 hari setelah jatuh tempo akan diikuti dengan penagihan pajak secara aktif yang dimulai dengan menerbitkan surat teguran.

Penagihan pajak aktif merupakan kelanjutan dari penagihan pajak pasif, dimana dalam upaya penagihan ini fiskus berperan aktif dalam arti tidak hanya mengirim surat tagihan atau surat ketetapan pajak tetapi akan diikuti dengan tindakn sita, dan dilanjutkan dengan pelaksanaan lelang.

c. Tahapan Penagihan Pajak

Beberapa tahapan dalam penagihan pajak, yaitu:

1) Surat Teguran, apabila utang pajak yang tercantum dalam Surat Tagihan Pajak (STP), Surat Ketetapan Pajak Kurang Bayar (SKPKB), Surat Ketetapan Pajak Kurang Bayar 
Tambahan (SKPKBT), tidak dilunasi melewati 7 (tujuh) hari dari batas waktu jatuh tempo (satu bulan sejak tanggal diterbitkannya).

2) Surat Paksa, apabila utang pajak tidak dilunasi setelah 21 hari dari tanggal surat teguran, maka akan diterbitkan Surat Paksa yang disampaikan oleh juru sita pajak Negara dengan dibebani biaya penagihan. Utang pajak harus dilunasi dalam waktu 2 × 24 jam.

3) Surat Sita, apabila utang pajak belum juga dilunasi dalam waktu $2 \times 24$ jam dapat dilakukan tindakan penyitaan atas barang-barang WP, dengan dibebani biaya pelaksanaan sita,.

4) Lelang, dalam waktu 14 hari setelah tindakan penyitaan, utang pajak belum dilunasi maka akan dilanjutkan dengan tindakan perlelangan melalui kantor lelang Negara. Dalam hal biaya penagihan paksa dan biaya pelaksanaan sita belum dibayar maka akan dibebankan bersama-sama dengan biaya iklan untuk pengumuman lelang dalam surat kabar dan biaya lelang pada saat pelelangan.

\section{METODE PENELITIAN}

\section{Teknik Analisis Data}

Metode analisis yang digunakan adalah metode deskriptif kualitatif, yaitu suatu metode dengan mengumpulkan data, menyusun, menginterpretasikan, dan menganalisis data yang telah diolah sehingga memberikan keterangan yang lengkap bagi pemecahan masalah yang dihadapi. Dalam penelitian ini, yaitu :
1. Menganalisis jumlah penagihan tunggakan pajak.

2. Menganalisis Penagihan tunggakan pajak atas efektivitasnya terhadap target.

3. Menganalisis kontribusi realisasi penerimaan tunggakan pajak terhadap saldo akhir tunggakan pajak

\section{PEMBAHASAN}

Pada bagian ini, peneliti membahas lebih rinci tentang penagihan pajak atas pencairan tunggakan pajak yang di lihat dari target serta realisasi pencairan tunggakan pajak KPP Pratama Batu terhadap penerimaan pajak pada Kantor Pelayanan Pajak Pratama Batu.

Tabel 1. Target pencairan tunggakan pajak KPP Pratama Batu Tahun 2012 - 2015

\begin{tabular}{|c|c|}
\hline Tahun & $\begin{array}{c}\text { Target Pencairan Tunggakan } \\
\text { Pajak (Rp.) }\end{array}$ \\
\hline 2012 & $7,402,648,579$ \\
\hline 2013 & 4.724 .231 .603 \\
\hline 2014 & 4.213 .693 .273 \\
\hline 2015 & 5.267 .116 .591 \\
\hline
\end{tabular}

Sumber : seksi penagihan KPP Pratama Batu, 2017

Berdasarkan tabel 1 target pencairan tunggakan pajak KPP Pratama Batu umumnya menunjukan target pencairan tunggakan pajak pada tahun 2012 mengalami peningkatan paling tertingi sebesar Rp. 7.402.648.579., dan terjadi penurunan terendah di tahun 2014 sebesar Rp. 4.213.693.273., Target pencairan tunggakan pajak ini yang sudah ditentukan oleh Kanwil dengan berbagai macam pertimbangan.Karena pada saat itu potensi piutang yang dapat dicairkan cukup besar sehingga targetnya juga besar, dan potensi yang dicairkan itu cukup kecil sehingga targetnya juga kecil.

Berikutnya diijelaskan tentang efektiivitas penagihan pajak. Efektivitas penagihan tunggakan 
pajak yang menunjukkan kemampuan dalam pengumpulan tunggakan pajak berdasarkan dengan jumlah penerimaan pajak atas bagian penagihan yang ditargetkan.

$\begin{gathered}\text { Efektivitas } \\ \text { penaghan Pajak }\end{gathered}=\frac{\text { Realisasi pencairan tungagakan pajak }}{\text { Target pencairan tungogakan pajak }} \times 100 \%$

Kriteria yang digunakan dalam menilai efektivitas penagihan pajak adalah :

Tabel 4.5

Klasifikasi Kriteria Nilai Efektivitas Penagihan Pajak

\begin{tabular}{|l|l|}
\hline \multicolumn{1}{|c|}{ Prosentasi } & \multicolumn{1}{c|}{ Kriteria } \\
\hline$>100 \%$ & Sangat Efektif \\
$90-100 \%$ & Efektif \\
$80-90 \%$ & Cukup Efekif \\
$60-80 \%$ & Kurang Efektif \\
$<60 \%$ & Tidak Efektif \\
\hline
\end{tabular}

Sumber : Depdagri, Kepmendagri No 690.900.327 Tahun 1996

Tabel 4.6 Realisasi pencairan tunggakan pajak KPP Pratama Batu
\begin{tabular}{|c|c|c|c|}
\hline Tahun & Tungaakan Pajak (Rp) & Persentase & Kriteria \\
\hline 2012 & 5.210 .737 .295 & $70,39 \%$ & Kurang Efektif \\
\hline 2013 & 2.858 .895 .943 & $60,52 \%$ & Kurang Efektif \\
\hline 2014 & 3.481 .090 .624 & $82,61 \%$ & Cukup Efekkif \\
\hline 2015 & 3.374 .804 .507 & $64,07 \%$ & Kurann Efekkiff \\
\hline
\end{tabular}

Sumber: Data diolah

Rata-rata realisasi penagihan tunggakan pajak atas target untuk tahun 2012 sampai dengan 2015 adalah sebesar 69,4\% yang masuk dalam kriteria kurang efektif.

Grafik 1.

Realisasi Pencairan Tunggakan Pajak KPP Pratama Batu

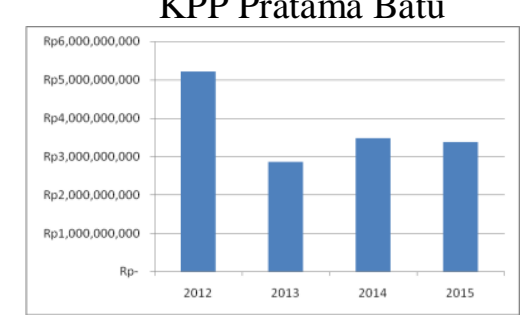

Berdasarkan Tabel 4.6 penerimaan pajak tunggakan tahun 2012 adalah paling tinggi yaitu sebesar Rp. 5.210.737.295 dan paling rendah adalah pada tahun 2013 yaitu sebesar Rp. 2.858.895.943.
Jika dilihat atas hasil realisasi pencairan atas target, tahun 2013 paling terendah yaitu sebesar $60,52 \%$ (kurang efektif) dan paling tertinggi tahun 2014 sebesar 82,61\% (cukup efektif).

Berdasarkan wawancara dengan prtugas bagian pelaksana seksi penagihan menjelaskan bahwa tinggi dan rendahnya realisasi lebih banyak disebabkan oleh kesadaran WP dalam membayar pajak, ditambah lagi dengan kondisi keuangan WP yang tidak mampu untuk membayar pajak.Hasil penelitian ini menunjukkan bahwa penagihan pajak atas tunggakan pajak belum optimal..

Perkembangan tunggakan pajak pada Kantor Pelayanan Pajak Pratama Batu tahun 2012 sejumlah Rp. 32.521.555.359,- ,di tahun 2013 mengalami kenaikan sejumlah Rp. 62.840.504.696,dan pada tahun 2014 mengalami kenaikan pula sebesar Rp. 63.630.133.678,- dan dan pada Tahun 2015 mengalami kenaikan sebesar Rp. 66.343.191.696. Disini terlihat jelas bahwa lonjakan yang paling tinggi adalah dari tahun 2012 ke tahun 2013 yaitu sebesar Rp 30.318.949.337.

Perkembangan Tunggakan pajak yang terbesar adalah dari tahun 2012 ke tahun 2013, disebabkan saldo tahun 2012 ditambah produk hukum yang diterbitkan tahun 2013 dikurangi pembayaran atau pengurangan pada tahun 2013. Untuk mengukur seberapa besar kontribusi penerimaan pajak yang berasal dari target pencairan tunggakan pajak yang di laksanakan oleh KPP Pratama Batu maka di gunakan rasio ini, dapat di ketahui apakah target pencairan tunggakan pajak cukup signifikan terhadap penerimaan pajak di KPP Pratama Batu.

Formula untuk Rasio pencairan tunggakan (RPTP) di KPP Pratama Batu adalah sebagai berikut :

RPTP $=\frac{\text { Realisasi tunggakan pajak }}{\text { Perkembangan tunggakan pajak }} \times 100 \%$


Tabel 4.7 kriteria kontribusi

\begin{tabular}{|l|l|}
\hline \multicolumn{1}{|c|}{ Klasifikasi Kriteria } & \multicolumn{1}{|c|}{ Kriteria } \\
\hline $0,00 \%-10 \%$ & Sangat Kurang \\
$10,10 \%-20 \%$ & Kurang \\
$20,10 \%-30 \%$ & Sedang \\
$30,10 \%-40 \%$ & Cukup Baik \\
$40,10 \%-50 \%$ & Baik \\
Diatas $50 \%$ & Sangat Baik \\
\hline \multicolumn{2}{|c|}{ Sumber : Depdagri, Kepmendagri No 690.900.327 tahun 1996 }
\end{tabular}

Perbandingan antara realisasi pencairan tunggakan dengan perkembangan tunggakan pajak di Kantor Pelayanan Pajak Pratama Batu. Perbandingan ini untuk menggambarkan seberapa besar kontribusi pencairan tunggakan pajak terhadap penerimaan pajak dari kegiatan penagihan pajak.

\section{Tabel 1.8 Kontribusi pencailan tunggakan pajak terhadap perkembangan}

tungagakan pajak pada KPP Pratama Batu

\begin{tabular}{|c|c|c|c|c|}
\hline Tahun & $\begin{array}{c}\text { Realisasip pencailan } \\
\text { tunngakakan (Ro) }\end{array}$ & $\begin{array}{c}\text { Salco akhir tungagakan } \\
\text { paiak (RD) }\end{array}$ & Kontitibusi & Kriteria \\
\hline 2012 & 5.210 .737 .295 & 32.521 .555 .359 & 16,029 & $\%$ \%) Kurang \\
\hline 2013 & 2.858 .895 .943 & 62.840.504.096 & & $\%$ Sangath Kurang \\
\hline 2014 & 3.481 .090 .624 & 63.630 .133 .678 & 5,479 & \% Sangat Kurang \\
\hline 2015 & 3.374 .804 .507 & 66.343.191.696 & 5,099 & $\%$ Sangat Kurang \\
\hline
\end{tabular}

Sumber: Datadiolah

Besarnya pengaruh realisasi pencairan tunggakan pajak penghasilan terhadap perkembangan tunggakan pajak di KPP Pratama Batu pada tahun 2012 sebesar 16,02\%. Untuk tahun 2013 sebesar 4,55\%, untuk tahun 2014 sebesar 5,47\%, tahun 2015 sebesar 5,09. Kontribusi terbesar adalah pada tahun 2012 dan terkecil adalah pada tahun 2015.

\section{Simpulan}

Berdasarkan analisis data dan pembahasan yang telah diuraikan pada bab empat, maka peneliti dapat menarik beberapa kesimpulan yaitu :

1. Efektivitas penagihan tunggakan pajak yang menunjukkan kemampuan dalam pengumpulan tunggakan pajak berdasarkan dengan jumlah penerimaan pajak atas bagian penagihan yang ditargetkan tergolong kurang efektif.

Keadaan tersebut disebabkan bahwa tinggi dan rendahnya realisasi lebih banyak disebabkan oleh kesadaran WP dalam membayar pajak, ditambah lagi dengan kondisi keuangan WP yang tidak mampu untuk membayar pajak. Hasil penelitian ini menunjukkan bahwa penagihan pajak atas tunggakan pajak belum optimal.

2. Besarnya Kontribusi realisasi penagihan tunggakan pajak terhadap saldo akhir tunggakan pajak pada KPP Pratama Batu tergolong sangat kurang efektif.

3. Tingkat perkembangan saldo akhir tunggakan pajak pada KPP Pratama Batu dari tahun 2012 sampai dengan tahun 2015 terlihat ada peningkatan. Hal tersebut merupakan pekerjaan rumah bagi Seksi Penagihan pada KPP Pratama Batu.

\section{Saran}

Berdasarkan simpulan, peneliti memberikan saran-saran sebagai berikut :

1. Kantor Pelayanan Pajak Pratama Batu agar harus lebih efektif dalam melakukan sosialisasi tentang manfaat pajak penghasilan, baik manfaat bagi Negara juga manfaat bagi masyarakat umum.

2. Kantor Pelayanan Pajak Kota Batuharus lebih persuasif dalam mengajak WP agar lebih sadar pajak

3. Kantor Pelayanan Pajak Kota Batu harus meningkatkan aktivitas penagihan atas tunggakan pajaknya.

4. Kantor Pelayanan Pajak Kota Batu harus melakukanjemput bola, maksudnya agar membuka kantor cabang di daerah Kota batu, Sehingga mendekat kepada WP. 


\section{Keterbatasan Penelitian}

Adapun keterbatasan dari penelitian ini yaitu sebagai berikut :

1. Obyek penelitian ini hanya pada WP yang terdaftar yang mempunyai tunggakan.

2. Penelitian ini hanya mengambil jangka waktu 4 tahunyaitu tahun 2012-2015 di KPP Pratama Batu.

3. Penelitian ini menggunakan data sekunder yaitu data yang telah diolah dari KPP Pratama Batu dan data wawancara dengan melihat daftar pencairan tunggakan dan saldo akhir tunggakan pajak sehingga dalam kesimpulan yang diambil berdasarkan data dari observasi \& wawancara.

4. Penelitian ini tidak memisahkan wajib pajak orang pribadi dan wajib pajak badan.

\section{DAFTAR PUSTAKA}

Casavera. 2009. Perpajakan.Edisi.Cetakan Pertama. Graha Ilmu. Yogyakarta.

Depdagri, 1996, Kepmendagri No. 690.900.327, Pedoman Penilaian dan Kinerja Keuangan.

Diana, Anastasia dan Lilis Setiawati. 2009 .Perpajakan Indonesia. Edisi kedua. Yogyakarta.

Guritno, 1992, Kamus Ekonomi, Jakarta: Erlangga

Ginting, Riskon. 2006.Pengaruh Pemberian Surat Penagihan terhadap Pembayaran Tunggakan Pajak Penghasilan. Jurnal Ekonomi \& Bisnis, Vol.5, No.1.

Gisijanto. 2008. Pengaruh penagihan pajakdan surat paksa pajak terhadap penerimaan pajak penghasilan badan. Jurnal Ekonomi Bisnis No. 2 Vol 13.

Hutagaol, John. 2007. Perpajakan Isu-isu Kontemporer, Jakarta: Graha Ilmu.

Irna febrianti. 2013 .Pengaruh kewajiban kepemilikan NPWP, Pemeriksaan Pajak dan
Penagihan Pajak Terhadap Penerimaan Pajak. Skripsi universitas islam negeri syarif hidayatullah jakarta.

Mardiasmo. 2011 .Perpajakan. Edisi Revisi. Yogyakarta.

Pardiat. 2008 .Pemeriksaan Pajak. Edisi Kedua. Mitra Wacana Media. Jakarta.

Prastowo, Yustinus. 2009 . Panduan Lengkap Pajak,Raih Asa sukses. Jakarta.

Purba, Arifanda. 2012 . Analisis Hasil Pemeriksaan Pajak Tahun 2008-2011 untuk Menentukan Pola Profil WP Badan yang Potensial di Kantor Pelayanan Pajak Pratama Jakarta Palmerah. Tesis Fakultas Ekonomi Universitas Indonesia.

Rahayu, Siti Kurnia. 2010 . Perpajakan Indonesia(Konsep dan Aspek Sosial). Cetakan Pertama. Graha Ilmu. Yogyakarta.

Resmi, Siti. 2014. Perpajakan Teori dan Kasus, Buku 1 edisi 8. Salemba Empat. Jakarta.

Salip dan Tendy Wato. 2006 . Pengaruh Pemeriksaan Pajak Terhadap Penerimaan Pajak(Studi Kasus: Di KPP Jakarta Kebon Jeruk). Jurnal Keuangan Publik, Vol.4, No.2.

Setiawan, Deddy Arief. 2007 . Analisis Hubungan antara Ekstensifikasi WP dan Surat Setoran Pajak dengan Penerimaan Pajak (Studi kasus pada KPP Jakarta Palmerah). Media Riset Akuntansi. Auditing dan Informasi. Vol.7, No.1

Soni dan Amelia Sandra. 2009 . Evaluasi proses pelaksanaan penagihan pajak dalam rangka pengamanan penerimaan pajak (studi kasus: Di KPP Jakarta XYZ).

Suandy, Early. 2008 .Perpajakan.Salemba Empat. Jakarta.

Sukirman. 2011 .Pengaruh Manajemen Pemeriksaan Pajak terhadap Penerimaan Pajak. Analisis Manajemen. Vol.5, No.1.

Sumarsan, Thomas. 2010 .Perpajakan Indonesia (Pedoman Perpajakan yang LengkapBerdasarkan Undang-undang Terbaru). Indeks. Jakarta. 
Tansuria, Billy Ivan. 2010 .Pokok-pokok Ketentuan Umum Perpajakan (KUP). CetakanPertama. Graha Ilmu. Yogyakarta.

Titin Vergirawati. 2011. Hubungan antara penerbitan surat Tagihan pajak dengan Penerimaan pajak (Studi Kasus: Di KPP Pratama Iiir Timur Palembang.

Undang-undang Nomor 28 Tahun 2007 tentang Ketentuan Umum dan Tata CaraPerpajakan.

Undang-undang Republik Indonesia Nomor 19 Tahun 2000 tentang Perubahan atasUndangundang Nomor 19 Tahun 1997 tentang Penagian Pajak dengan Surat Paksa.

Waluyo. 2009 . Perpajakan Indonesia. Salemba Empat. Jakarta.

Zakiah. Hartono Arief. 2008 . pengaruh penagihan pajak dan surat paksa pajak terhadap penerimaan pajak penghasilan. Jakarta 